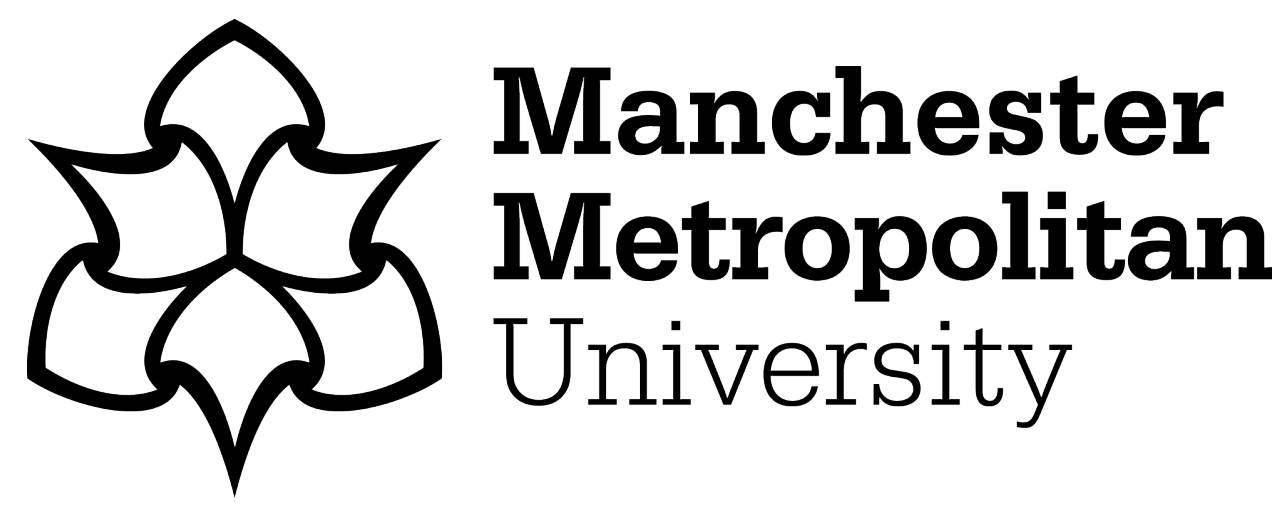

Parker-Strak, R, Barnes, L, Studd, R and Doyle, S (2020) Disruptive product development for online fast fashion retailers. Journal of Fashion Marketing and Management, 24 (3). pp. 517-532. ISSN 1361-2026

Downloaded from: https://e-space.mmu.ac.uk/625693/

Version: Accepted Version

Publisher: Emerald

DOI: https://doi.org/10.1108/JFMM-08-2019-0170

Please cite the published version 


\title{
Disruptive product development for online fast fashion retailers
}

\author{
Rachel Parker-Strak \\ Department of Materials, The University of Manchester, Manchester, UK \\ Liz Barnes \\ Manchester Fashion Institute, Manchester Metropolitan University, Manchester, UK, \\ and

\section{Rachel Studd and Stephen Doyle} \\ Department of Materials, The University of Manchester, Manchester, UK

\begin{abstract} fast fashion online retailers who are developing "own label" fashion clothing. With a focus upon inputs, outputs, planning and management in order to comprehensively map the interplay of people, processes and the procedures of the product development process adopted.
\end{abstract} \\ Purpose - This research critically investigates product development in the context of
}

Design/methodology/approach - Qualitative research method was employed. Face-to-face semi structured in depth interviews were conducted with key informants from market leading fast fashion online retailers in the UK.

Findings - The major findings of this research demonstrate the disruptions in the product development process in contemporary and challenging fashion retailing and a new "circular process" model more appropriate and specific to online fast fashion businesses is presented.

Research limitations/implications - The research has implications for the emerging body of theory relating to fashion product development. The research is limited to UK online fashion retailers, although their operations are global.

Practical implications - The findings from this study may be useful for apparel product development for retailers considering an online and fast fashion business model.

Originality/value - The emergent process model in this study may be used as a baseline for further studies to compare product development processes.

Keywords - Fashion industry, Product development, Online fast fashion

Paper type - Research paper 


\section{Introduction}

In a highly competitive and globally integrated world, retailers are continually seeking ways to be more flexible, efficient, and targeted in their processes (Kincade, Gibson and Regan, 2007). The development of new products is a core activity within the fashion industry. Increasing the frequency and 'newness' of fashion collections has become crucial for the survival of many fashion companies (Tran, Hsuan and Mahnke, 2011), this is putting additional pressure on fashion retailers to have an effective and efficient product development process in order to deliver the products consumers expect. The rapid changes in consumer demands and technological advancements have impacted the fashion industry in a variety of ways yet the consequences of these changes on the fashion product development (FPD) process is yet to be fully explored in the existing literature. There is limited research in the specific field of fashion product development, with relatively few current theoretical models (Goworek, 2010; d'Avolio, Bandinelli and Rinaldi, 2015; Silva and Rupasinghe, 2016; Moretti and Braghini Junior, 2017), that address the management of the process of product development. The existing literature on the fashion product development process demonstrates the core activities and tasks that are part of the procedure in detail and it illustrates the process as a generic form, suggesting that it is the same for all fashion retailers and all types of products. It does not consider the changes and challenges in the contemporary fast fashion sector such as the rapid speed to market, increasing consumer demands, challenging product quality(Barnes and Lea-Greenwood, 2006; Bhardwaj and Fairhurst, 2010; Caro and Martinez, 2014) and how that may impact the process when developing products. The literature portrays the product development process of fashion garments as the same process for all retailers regardless of their product and consumer type, preferred retail outlet, market level and business model.

For all fashion retailers' there has been an increase in consumer demand for products that reflect the latest trends and are available to buy immediately (Barnes and Lea-Greenwood, 2006; Bhardwaj and Fairhurst, 2010). These aspects coupled with the motive to decrease lead times are changing how retailers traditionally worked within the fashion product development process. It is becoming increasingly impossible to deliver the right product at the right time for the right consumer when the lead-times to do so are within a matter of two to three weeks. This drives the 
need for retailers and researchers to understand the most effective methods of developing products and delivering them to the consumer in the quickest time possible. Considering how to manage and control the product development process is vital to the success of a retailer. This is of particular interest for online fast fashion retailers, a growing area in the fashion industry, that have larger product portfolios and shorter lead-times than fast fashion retailers who trade with physical and online retail outlets. Increasingly, online fashion websites are even more capable than physical stores of successfully and innovatively conveying to the customer up to date trends and sharing cutting edge fashion advice.as well as converting this interest into sales (McCormick and Livett, 2012) The aim of this research is to critically examine the role, nature and management of product development within online fast fashion retailers. The complex process, its multidisciplinary nature, and how it is managed is the prime subject of this investigation and will conclude with suggestions of a new fashion product development process model specific to a business type. This is a new contribution to the literature in the Fashion Product Development field focussing specifically on online fast fashion retailers.

\section{Fast Fashion On-line Retailers}

The online fast fashion sector has become a major part of the UK fashion high street. These retailers are the highest in popularity in the youth fashion market, with three out of four $(77 \%)$ womenswear consumers aged between16-24 years having shopped online for clothing in the last year (Mintel, 2019). E-commerce and mcommerce have changed the fashion retail landscape; consumers have enthusiastically adopted online retail as a preferred way to shop in some cases (McCormick et al., 2014). Pure-play retailers now capture an estimated $12.3 \%$ of consumer spending on clothing and accessories within the UK in 2018, with ASOS, Boohoo and MissGuided having a small but growing impact on the UK sector (Mintel, 2018). These pure-play retailers are racing ahead in online sales (Nash, 2019) having the competitive edge across the market, and using social media to aid the interaction between consumers and fashion garments online to impact and increase sales (McCormick and Livett, 2012). More than ever there is a great emphasis on products being in the right place at the right time to satisfy consumer demands. Fast fashion retailers are continually delivering new products for sale in order to keep up with the increased demand that in some cases they have created themselves via the 
social media interactions with consumers. They seem to have a much more reactive and consumer driven process of product development that acts at a rapid speed.

Fast fashion online retailers have a much larger amount of products available to consumer as they are not limited by the store environment, and have much faster lead-times than fast fashion retailer who have physical and online outlets; they are able to use the lack of physical stores to their advantage. Always having an available space for new products means that they are able to increase product assortments without hesitation or concern for space to display these new lines and ranges. Their product offering available to consumers is therefore double or triple the size of fast fashion retailers who trade with physical and online stores, see figure 1.

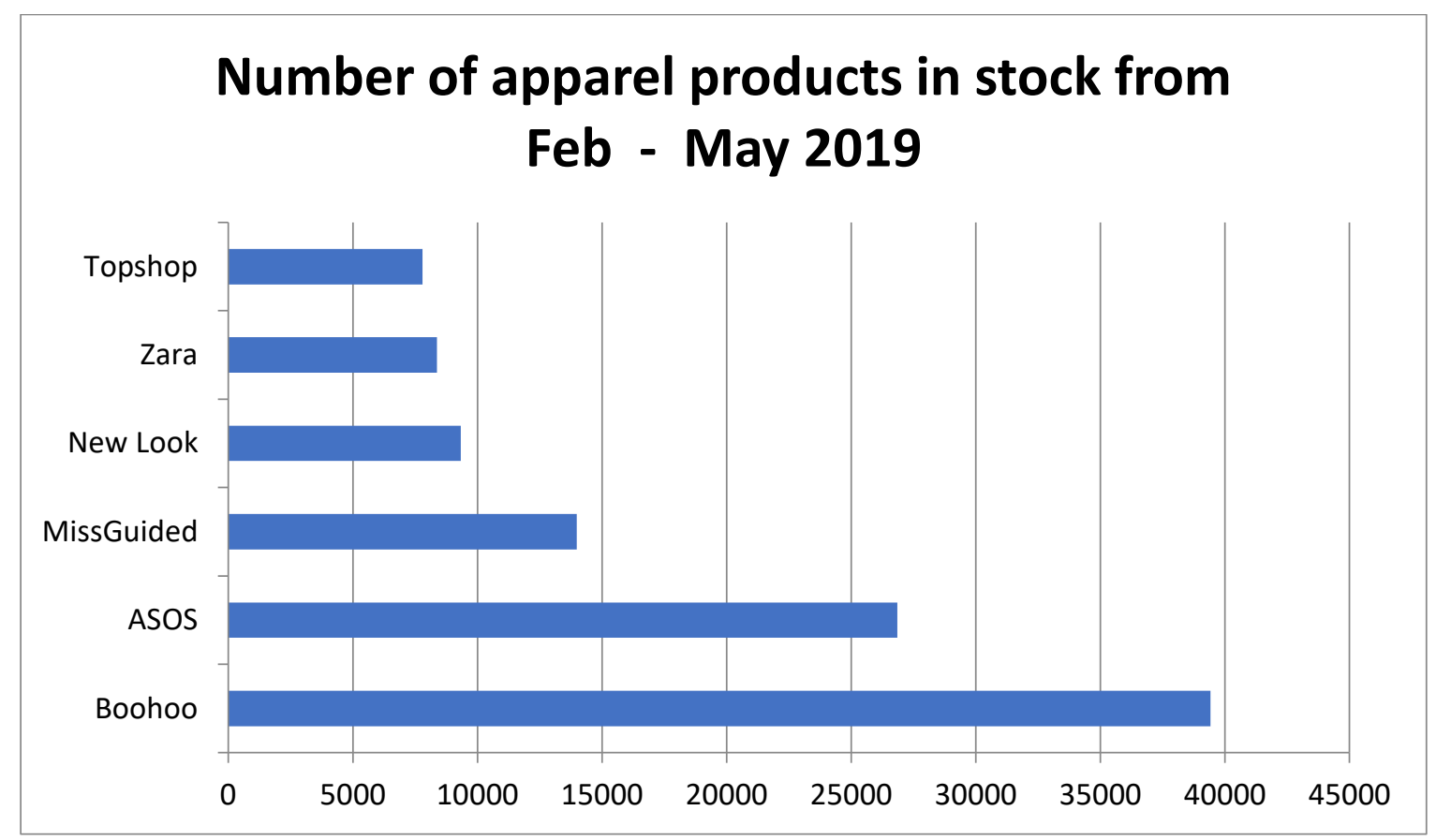

Figure 1: Number of apparel products excluding footwear and accessories available online from $1^{\text {st }}$ February to $1^{\text {st }}$ May 2019 data retrieved from Edited.com (Edited, 2019)

The lack of physical retail outlet also allows product orders to be significantly smaller in quantities and from a more local supply base which therefore decreases the manufacturing lead-times to as little as a few weeks. Fast fashion is a known business strategy which aims to reduce the processes involved in the buying cycle and lead times for getting new fashion product into stores, in order to satisfy consumer demand at its peak (Barnes and Lea-Greenwood, 2006). As online fast 
fashion retailers are becoming increasingly dominant within the fashion industry, with recent increased growth and demand. How these larger product assortments and shorter lead-times are influencing the product development process is unknown and is the priority of this investigation. In order to understand and investigate fashion product development there is a need to understand the context in which it operates. Having a complete understanding of the consumer, their lifestyles, consumption behaviours and motivations will drive a more effective initial product development process and improved retail performance (Bhardwaj and Fairhurst, 2010).

\section{Fashion ‘Own Label’ Products}

In order to truly understand the fashion product development process and the tasks and activities that are part of it, it is important to establish what own label products are and why they are more dominant within the fashion industry. "Own label" refers to the development of a product from the initial idea stages right through to manufacturing and is owned and prioritised by fashion retailers. This type of product is the preferred method for the majority of products for fashion retailers within their ranges. The strength of the own label product for online fast fashion retailers such as ASOS, Boohoo and MissGuided has improved the brand equity of these retailers and they have a reputation of being fashion forward brands that deliver on trend products at exactly the right time at a competitive price. Delivering specifically styled products at a rapid speed and specific price point requires ownership of the creative process of a product and therefore make 'own label' products the priority for retailers. This form of product development is also rewarding financial for retailers, these products command a much larger margin and therefore much more financially favoured. How 'own label' products are designed and produced mean that the retailers' in-house product development resources are now highly extensive and skilled (Grose, 2012). This has also created a demand for creative product development skills (Goworek, 2010) that is challenging the traditional fashion product development business model where the creative elements were the responsibility of the supplier. The management and development of these processes are crucial to the achievement and success of getting the right products at the right time in front of consumers to achieve the greatest margins. It is this 'own label' product development that is a principal interest of this research. The larger number of products and the rapid lead times to manufacture and deliver is crucial to the 
success for online fast fashion retailer. Yet it is unknown if the product development process used has been challenged, simplified or modified for online fast fashion retailers to meet their business objectives. The use of enhanced design and quick response strategies for fast fashion retailers has been seen to improve process and increase profits (Cachon and Swinney, 2011). This investigation is exploring if the product development process has been impacted too.

\section{Fashion Product Development literature}

Fashion Product Development is a process specific and unique to the apparel industry although it draws some parallels with generic product development theory and research that we see in the New Product Development field. Fashion product development is the strategic planning of goods using the key areas of creative, technical, production, and distribution (Keiser and Garner, 2012). Research has also been critical of the process, it is a knowledge-intensive set of tasks that needs to be improved in order to enhance a company's competitive advantage, as the complexity and variety of products increase, so does the need for knowledge and expertise for developing products (d'Avolio, Bandinelli and Rinaldi, 2015). Communication skills become particularly significant to enable effective collaboration during fashion product development, with the current speed of technological change and import penetration approaching saturation in the UK fashion market, key players need to have increasingly flexible market knowledge and communication skills in conjunction with creativity (Goworek, 2010). The literature discusses and illustrates fashion product development as a generic form, applicable to all types of retailers, regardless of what level of the market they compete in, who their consumer is and what type of product they deliver. This investigation challenges that there is a generic form of fashion product development and the complex differences in the various types of retailers that compete in the fashion industry will reflect in different product development processes that are used in contemporary fashion retailing.

Process models of FPD have been developed by several authors (Gaskill, 1992; Lamb and Kallal, 1992; May-Plumlee and Little, 1998, 2001; Lea Wickett, Gaskill and Damhorst, 1999; Pitimaneeyakul, Labat and Delong, 2004; Goworek, 2010; Moretti and Braghini Junior, 2017).They are of departmental stage in nature and portray the process in a sequential and linear format. They illustrate the product moving through 
a series of stages that are completed before progressing to the next. The models portray the process as a detailed overview of activities and tasks and in some cases lines of communication in a sequential and logical manner. The fashion product development process follow the approximate chronological sequence in which they usually occur, although several elements can overlap temporarily (Goworek, 2010) and the process models portray this. Tyler et al (2006) observe that product development in the textile and clothing industry has been characterised by functional independence with each participant within the process contributing to the procedure sequentially, the issues with fashion product development are with lead times and communication between the different functions. There is a need for a more practical new product development model for apparel, and this should evolve as the result of empirical studies (Silva and Rupasinghe, 2016). With the challenges of speed and time and the influence of fast fashion, this research explores whether sequential processes are appropriate and relevant in a market where speed is so critical. There are limitations in the existing models of fashion product development for fast fashion online retailers; the models explore the process much more generally, they do not address lead-times and product differences and types and how this can be managed within a process. Online fast fashion retailers are recognised in industry as significantly different with distinctive business objectives, supply chain strategies and brand ideals. Therefore investigation into their fashion product development process is crucial to understanding if their differences impact the generic process that is available in current literature.

The more established models form the existing knowledge and basis for this research. Apparel Product Development Process (APDP) model (Moretti and Braghini Junior, 2017) and No-Interval Coherently Phased Product Development model for apparel (NICPPD) (May-Plumlee and Little, 1998) give a strong overview of the activities and tasks within the process. They have been based on the previous process models and are detailed but do not really address the management or organisation of the process. They are current and detailed and address the process, showing the set tasks and stages in a sequential order but they do not consider the time scales, product lifecycles or type. Nor do they explore how the difference in speed and product can influence the way in which a product will transition through the process of development. .The No-interval coherently phased development model 
for apparel (NICPPD) (May-Plumlee and Little, 1998) is an extremely detailed model that gives understanding of the critical convergent points, concurrent process and porous phase boundaries (May-Plumlee and Little, 1998). The model itself is too detailed to be viewed in its entirety and claims to aim in the building of organizational structures required to effectively execute the process. However strategically managing and optimizing the process is of vital importance (May-Plumlee and Little, 1998) which is not addressed nor discussed within the overview or in the detailed phases. The Apparel Product Development Process (APDP) model (Moretti and Braghini Junior, 2017) is the latest most current theoretical model yet. This model intends to address the lack of organization of the activities performed during the process, the difficulties in the relationships between departments and the lack of time for a research stage (Moretti and Braghini Junior, 2017). The macro and micro phases of this model again just give indication of the activities and tasks addressed throughout the process but no suggestion of management and organisation of this process. Again, the process is recorded in a sequential and departmental manner.

Product and process integration and cooperation is a much more successful product development process (Boujut and Laureillard, 2002), however despite Goworek (2010) proposing that the process requires cooperation and coordination, the literature and existing models of FPD do not address this and fundamentally they do not link or draw on the work from other sectors, theories or industries. It is productive for apparel industrialists to adopt and adapt product development strategies from other manufacturing industries (Silva and Rupasinghe, 2016). Here lies the gap in the literature, which is the focus for this research and development of a new theoretical model drawing on theory from generic New Product Development (NPD) theory to underpin a new perspective or model for fashion product development specifically for online fast fashion retailers.

Using the fashion product development models discussed previously as a starting point, the gaps in the literature regarding the management and organisation of the process can be examined and other disciplines may be used to explore how to advance this field of research in explaining fashion product development. New product development research is a more advanced area of research that is non discipline specific. It is the process models of this field that are of interest for this research, they encapsulate the many tasks involved from generating and evaluating 
the new products from development through to physical products (Hart 1996). Models over this vast research agenda have been categorised by Saren (1984) and Trott (2008) and have been reviewed in the development of the APDP model (Moretti \& Braghini Junior 2017) and the work of Silva and Rupasinghe (2016). The models of Network (Trott, 2008), Multiple Convergent (Hart and Baker, 1994) and Evaluation (Mahajan and Wind, 1988) and are a particular interest to this study as they give an different format for a process model. The Hour Glass Model of Innovation (Vojak et al., 2010)is also of interest as this model is not a process to be followed like a recipe, but a collection of recursive, iterative, contingent activities (Vojak, Price and Griffin, 2012). Collectively they give an alternative format for model layout and the lines of communications as well as the ability to progress through the stages of the process in a non-linear way. New product development models and associated theories may not be specific to the apparel fashion industry but may offer some interesting ideas on concepts that can be utilised and applied to fashion product development models. Research in product development must be tightly motivated by the needs of industrial practice and is essentially a commercial function, and therefore most knowledge about product development does not have much meaning outside of the commercial realm (Krishnan and Ulrich, 2001).

It is these additional research ideas and management information that are not specific to the apparel industry that may give a more realistic and applicable business process model for online fast fashion retailers. Fashion product development is not sequential but a series of linked activities that overlap, requires concise planning for time, resources and people to address the implications of demand and speed. As the process is a continuous one these considerations need to be managed to maintain the most effective methods and processes are used to address the challenges facing industry. Understanding how such a traditionally complex and time consuming process is being managed within such a rapid time frame that online fast fashion retailer adheres to is a priority for this investigation.

This varied form of product development influenced by product and business type is the gap in the literature and how this research will contribute. There is no indication or discussion on the management of the process, or acknowledgement of business or product type in fashion product development research papers. Which is the focus 
of this investigation; are the fashion product development process models relevant to the Online Fast fashion business model?

\section{Methodology}

Qualitative research is focused on understanding the "insider's perspective" of people and their cultures and this requires direct personal and often participatory contact. (Antwi and Kasim, 2015) For this investigation data was collected via twelve individual semi structured in-depth interviews of approximately one hour to ninety minutes taken between. December 2017 and December 2018 . These interviews were conducted with Buyers, Merchandisers or Designers at various levels from assistant to more senior roles; all interviewees had experience within and participated in the Fashion Product Development process for their job role. The interviews took place within the workplaces of the participants from three online fast fashion retailers; detailed in table 1 . The aim of the research was to gather an authentic understanding of peoples experiences of the fashion product development process and the open ended questions were the most effective route towards this (Silvermann, 2014), as too being within their own environment.

\begin{tabular}{|l|l|l|l|l|}
\hline Retailer & Interviewee 1 & Interviewee 2 & Interviewee 3 & Interviewee 4 \\
\hline A & $\begin{array}{l}\text { Assistant Buyer } \\
\text { (A1) }\end{array}$ & Buyer Admin(A2) & $\begin{array}{l}\text { Assistant } \\
\text { Merchandiser (A3) }\end{array}$ & Designer (A4) \\
\hline B & $\begin{array}{l}\text { Buyer Assistant } \\
\text { (B1) }\end{array}$ & $\begin{array}{l}\text { Assistant } \\
\text { Merchandiser (B2) }\end{array}$ & Buyers (B3) & Designer (B4) \\
\hline C & Buyer (C1) & Merchandiser (C2) & Buyer Assistant (C3) & $\begin{array}{l}\text { Assistant } \\
\text { Merchandiser (C4) }\end{array}$ \\
\hline
\end{tabular}

Table 1, Breakdown of sample taken between December 2017 - December 2018 The three companies chosen are considered leading retailers in the UK using the fast fashion online business model and successfully trading internationally with large numbers of growing customers. They are considered as UK based retailers trading in womenswear and menswear. They all trade exclusively online and have considerable and reputable experience within the industry; they share the same target market and have large numbers of product options and high engagement in social media dialogue with consumers. The participants were chosen due to their experience and knowledge of the product development process and then therefore 
would give a rich set on in-depth data that fully addressed the objectives of this study. An appropriate sample size in qualitative research is only really answerable within the context and scientific paradigm of the research being conducted. (Boddy, 2016). Four different participants per company were interviewed each with different job roles and prior experience, working in different product departments and contrasting product categories of dresses, jumpsuits, accessories, jersey tops and knitwear within womenswear. Therefore, a varied set of experiences of the fashion product development process was investigated and recorded. This gave the discussions much more authenticity as the priorities of each of the categories will be shared in some parts but have different challenges in others. However obtaining data of any sort is not a neutral activity, an interview may bring particular issues to the fore for the interviewee, or the process might lead the interviewee to new insights of their situation (Bazeley, 2013).

This research takes a social constructivist approach focusing on the people, individually and collectively and their different experiences and situations and how these impact communications and participation of the fashion product development process. There is an emphasis on the rhetorical and constructive aspects of knowledge and the realisation that facts are socially constructed in particular contexts (Silvermann, 2014).It is the experience of the process of fashion product development that is of specific interest for this investigation, stress is placed upon the importance of listening, on the researcher trying to suspend their preconceptions and prejudices in order to understand the perspectives, feelings or accounts (Hammersley, 2013). However, assessing qualitative research through a social constructionist lens is premised upon the belief that research findings are always already partial and situated; that they actively construct the social world which is itself an interpretation and in need of interpretation(Aguinaldo, 2004).

Interview answers are shaped by the questions asked, even in relatively unstructured interviews what is said is influenced by other aspects of the interactional process (Hammersley, 2013). The questions addressed were catagorised into nine specific themes listed below.

\section{Fashion Product Development Process}


2. Communication

3. Assortment Breakdown

4. Fashion Product Development Stages

5. Issues and Risks

6. Key Players

7. Solutions and Outcomes

8. Technology

9. Time and Speed

The themes supported the organic discussions that took place with a form of structured format and clarifying that the key areas identified within the prior literature reviewed was acknowledged whilst still allowing for free-flowing discussions to take place. Situational information relating to specific events or experiences, including the physical settings in which particular events occur, the timing of events, or changes in circumstances, will vary throughout data sources and will influence the data collected (Bazeley, 2013). There was also an opportunity for the participant to address any other potential additional information that could support, challenge or influence the fashion product development process. Potentially this could enable additional research areas or questions to be considered. Having the opportunity to probe for alternative meaning or answers will add more significance and depth to the data, and hopefully lead to alternative areas of discussion. Qualitative research often concerns developing a depth of understanding rather than a breadth(Boddy, 2016)

Thematic analysis was used to find links and connections within the data using NVivo software. The process of coding using software encourages an attention to detail and constant review of the data (Bazeley, 2013) The use of thematic codes identified in data provides a useful starting point to understand the fashion product development processes within online fast fashion retailers, however effective analysis requires using data to build a comprehensive, contextualised and integrated understanding or theoretical model of what has been found , with an argument drawn across the data that establishes the conclusions drawn (Bazeley, 2013). 


\section{Findings}

From the data collected within the nine themes, the findings established four key areas of new knowledge;

- Additional and disruption of stages added to the Fashion Product Development process

- Issues and Challenges during the Studio stage

- Product Assortment breakdown

- Fashion Product Development Stages and Process

\section{Additional and disruption of stages added to the fashion product development process}

The discussions with all twelve participants established that there is an additional stage in the fashion product development process in online fast fashion retailers. Interviewees describe this as the Studio stage. This differs from the previous fashion product development literature and the process models Apparel Product Development Process (APDP) (Moretti and Braghini Junior, 2017) and No-Interval Coherently Phased Product Development model for apparel (NICPPD) (MayPlumlee and Little, 1998). Interviewees B1, A3 and C3 specifically address the inclusion of the stage as part of the process but also the issues concerning the activities within it and the logistics of having an additional stage in such a challenging and time starved process.

The "Studio has really become part of the product development process especially for an on-line retailer, the styling of a product is so key as it's the only way to promote sales. Not styling correctly or even using the wrong model can impact and damage sales. It is an important aspect of the Buying Cycle for on-line fashion retailers". $(B, 1)$

Where everything is becoming more and more digital, studio is becoming more and more important. (C3)

Essentially, we've seen scenarios where we have done our part, got the product to them in the time ready but studio couldn't deliver it, so our 
product finally landed a month later, so essentially, we lost the sales in the previous month and when they did land, we didn't do so well as it was completely the wrong time of the year. The difference within 4 weeks is huge you can completely miss it $(A, 3)$

"Studio" represents the term given to the stage when the completed product would be photographed ready to "go live" and then be added to the transactional website of an online retailer. The key activities within the Studio stage are photographing the gold sealed samples that are identical to the products in the manufacturing stage, this is carried out by participants such as photographers and stylists, who are not traditionally part of the fashion product development process but it would seem are now key players. The styling of the product is also essential to maintain the best potential look to ensure maximum selling opportunity, this was addressed by B1 as a crucial part of the stage. Post production activities such as 'photoshopping' the images to make sure they are of correct standard and uploading imagery and product information so the products are ready to "go live" are also recognized as part of the Studio process and crucial elements for the product to be ready for sale. It is vital that all these activities are completed within the timescale and deadline initially planned, so products are not late for sale and therefore reach the market and are sellable within the available selling time to achieve maximum potential sales.

Participant A3 specifically highlighted how this can negatively impact the final outcome if not achieved.

Without the Studio stage the products cannot be realized through to the purchase decision. Not only did the Studio stage potentially causes significant disruption to the whole process as addressed by participant A3 and B1 and it appears to be vital to the overall business model of online retailers. Causing more issues with communications and lead-times which is already recognized as challenging within the fashion product development process (Tyler, Heeley and Bhamra, 2006)

"Each week we would pull together a report that told us which products were in the warehouse but not actually online so then we would send that over to Studio as a priority list. It is very frustrating if a product is not shot and sat waiting in the warehouse; all the efforts to get products for the right price at the right time are undone". $(B, 1)$ 
The Studio stage is not considered a new activity for some types of fashion retailers. Mail order retailers have always acknowledged the activity as a crucial part of the business. Goworek (2007) addresses the process and challenges the studio stage has on buyers of mail order ranges, whilst they are not directly involved with the process it is useful to be aware of them as they have an influence on product sales. Buyers are under pressure to ensure that the products that are manufactured in bulk are identical in style and colour to the sample that has been photographed and are delivered on time in order to satisfy customers, these are issues that are less significant for retailers with store environments (Goworek and McGoldrick, 2015). However considering the studio stage as part of the Fashion Product Development process is a new contribution to literature.

Speed and time are factors that challenge the process of fashion product development; developing products in a limited amount of time magnifies how efficient a process is and could or should be. With this in mind it is evident that the Studio stage has suddenly become an important element of the process. Keeping this stage external to the process reverses the efforts made to combat challenging lead-times. Therefore, causing a disruption in the fashion product development process; recognising that the Studio stage is part of the process is crucial for online fast fashion retailers. Identifying that the stage interacts with and influences the product development process is a much more realistic view of the fashion product development process. Highlighting that cooperation and coordination (Goworek, 2010) within the product development process for online fast fashion retailers is evident .

\section{Issues and Challenges during the Studio stage}

The findings identified that the additional stage of Studio takes place parallel with the manufacturing stage. This is done to initially save time as the two activities can be done in conjunction and to increase the speed of the overall process wherever possible. It would also mean that all preparations prior to product launch can be finalized and once the product is delivered from the supplier, the product is therefore ready for sale. However due to breakdown in communication and a backlog of work, in many cases the Studio stage is being delayed until end of process, therefore after the manufacturing stage It was highlighted that the participants in the Studio 
stage were very disconnected to the other participants within the fashion product development process. They did not realise their importance within the product development process and therefore the relevance of meeting deadlines with accuracy. . The solutions suggested by participant A1 addressed the issues with communication between the traditional participants of the fashion product development process and the new or 'accidental' members. This supports and acknowledging that the Studio stage and its participants need to be included within the overall process, and also clearly communicated with launch dates, product priority and the potential styling requirements.

"We started to have meetings collectively, we got to see how they work down at the studio which really helped, and we can see them any time now and have the discussions regarding stock face-to-face so were able to all understand the purpose of the product and how we like them to be shot". $(A, 1)$

"It's important to keep your product development always visible for Studio so they can understand your design ideas how you intended the product to look for example" (A.1)

Collective communications not only improved the transparency of the stages such as range development and finalization for the new participants from the Studio stage, but it was also suggested that it enhanced the management and efficiency of the fashion product development process. Clearer and structured communications have enabled the participants to become more engaged and develop a more detailed understanding and a greater knowledge of each of the departments and their challenges and activities. The result of this fluid communication is a more streamlined approach to managing the accuracy of the timelines within the product development process. This more inclusive and flexible application of managing the product development process has challenged the issues of disruption as well as adopting and addressing 'new' participants within the procedure. Companies are reinventing their development processes to become faster, leaner, and more effective while simultaneously improving smaller components within the stages of the process(Silva and Rupasinghe, 2016). 


\section{Product Assortment breakdown}

Due to the rapid speed of which the online fast fashion retailers move through the fashion product development process it became clear that some initial pre-process decision making takes place. The product assortments developed by each of the three retailers are categorised to improve the speed of the process from idea to manufacture. This product categorisation allowed for a much faster and more precise decision-making system for the organisation of the product development process. It was highlighted by the participants B1 and C3 that not all products need to go through the full process, a concept that has not been previously addressed within the existing fashion product development literature The product categories would influence the supplier choice, maximum and minimum lead-times and necessary stages of the fashion product development process for each of the products within an assortment. From the interviews conducted the product assortment for a season (January to June or August to December) would consist of the following categories;

Own label forward order products; products within this category would have a maximum lead-time of eight weeks from concept to delivery. As it would be necessary for this product type to go through the full product development process, and engage in activities within each of the stages.

In-season bought products; - products within this category are developed and ordered during the trading season so the live sales data can heavily influence the reactive decision making on which products to develop. To aid in this decision making retailers will utilise the supportive relationships held with suppliers that can accommodate the quick turnaround of manufacturing new products line, using previous product specifications and past successful lines as a starting point for development to speed up the process and streamline costs and efforts required. This product type went through the later stages of the product development process because the creative earlier stages where not necessary. Wholesale bought or Supplier products; products within this category are items that are ready made products purchased directly from suppliers. Therefore as all the creative and technical stages have been initiated by the supplier it allows for these products to skip the majority of the product development stages.

"Product classification influences which stages within the fashion product development can be skipped".(B1) 
"I would say there is only twenty percent of the whole range that we are taking through the full product development process where the starting point of reviewing ranges, looking at trends then developing the product through design then sampling".(C3)

This information on product assortment has changed the traditional fashion product development process that online fast fashion companies are using. Pre-process categorisation of products can dictate how a product moves through the product development process. Therefore, confirming that not all products are the same and require a more varied treatment through the fashion product development process. This illustrates that a much more flexible approach and understanding initially that the product can influence the type of process required. Restructuring the design process not just the manufacturing process is key to successful and competitive business advantage (Doris, Kinade and Gibson, 2007).

\section{Fashion Product Development Stages and Process}

In previously documented models all products begin in the same position and move through the process model in the same sequence (May-Plumlee and Little, 1998; May-Plumlee and Little, 2006; Goworek, 2010; Moretti and Braghini Junior, 2017). However, in reality as stated by participant A2 products are skipping or repeating stages of the process in order to mitigate or eradicate any issues with speed or time scales.

"It's not linear at all you may jump steps, we also may go backwards again, you need to move backwards and forwards much more fluidly". $(A, 2)$

However, there are risks with garment fitting and quality associated with the method of skipping stages within the fashion product development process and participants are fully aware of this but are prepared to manage them where possible in order the achieve the fixed deadlines and maximise sales possible. It was clear that the fashion product development process used within online fast fashion retailers is more reflective of the new product development models previously discussed. This more fluid and circular format of the process is reflective of the Network Model 
(Trott, 2008). Stages occurring simultaneously and continuous lines of communication depict the models of Multiple Convergent Model (Hart and Baker, 1994) and Evaluation Model (Mahajan and Wind, 1988). It was evident from the participants A1, A2, C1 that there were continuous stages within the process such as the Research, Review and Planning activities and Range Finalisation. These continued stages address and support communications and align decision making with deadlines within the process.

"We work so fast we must continually review everything so we're able to add things quickly but also drop things if they are not working out". $(A, 2)$

"The process that I'm involved in is not linear or sequential at all.

Stages are happening at the same time such as research and planning and range review". $(\mathrm{A}, 1)$

"The stage doesn't start or stop its continuous, especially if there is an issue you are expected to be reactive and derisk as much as you possibly can". (C,1)

From these finding it has also become evident that the fashion product development process used in online fast fashion retailers has become more circular rather than sequential or linear as previously depicted in literature. There is also a fluid flow of information and communication allowing the products to move in different directions through the process as required. A more flexible and agile process of product development seen in online fast fashion retailers can be considered as a new way to manage and conducting the fashion product development process. Reflective of the Hour Glass Model of Innovation (Vojak et al., 2010) as more of a collection of recursive, iterative, contingent activities rather than a step by step process. From a management perspective having a more fluid and transparent process could certainly be supportive of time, people and resource planning as new apparel product development models require collaborative engagement (Silva and Rupasinghe, 2016). As the rapid speeds, accelerated timescales and the increasing number of reactive products being developed in season to appease driving consumer demands impacts more retailers, a more fluid and circular method of managing the product development process is beneficial for perhaps all types of fashion retailer. 
Online fast fashion retailers have developed a much more agile and flexible fashion product development process to reflect their working patterns. Their choice of retail outlet has a direct impact on the process, and it is revealing how much the product development process has changed due to the very end of the supply chain.

Figure 2 illustrates how these findings are used to produce a new theoretical model of Fashion Product Development Process (FPDP) for Online Fast Fashion Retailers.

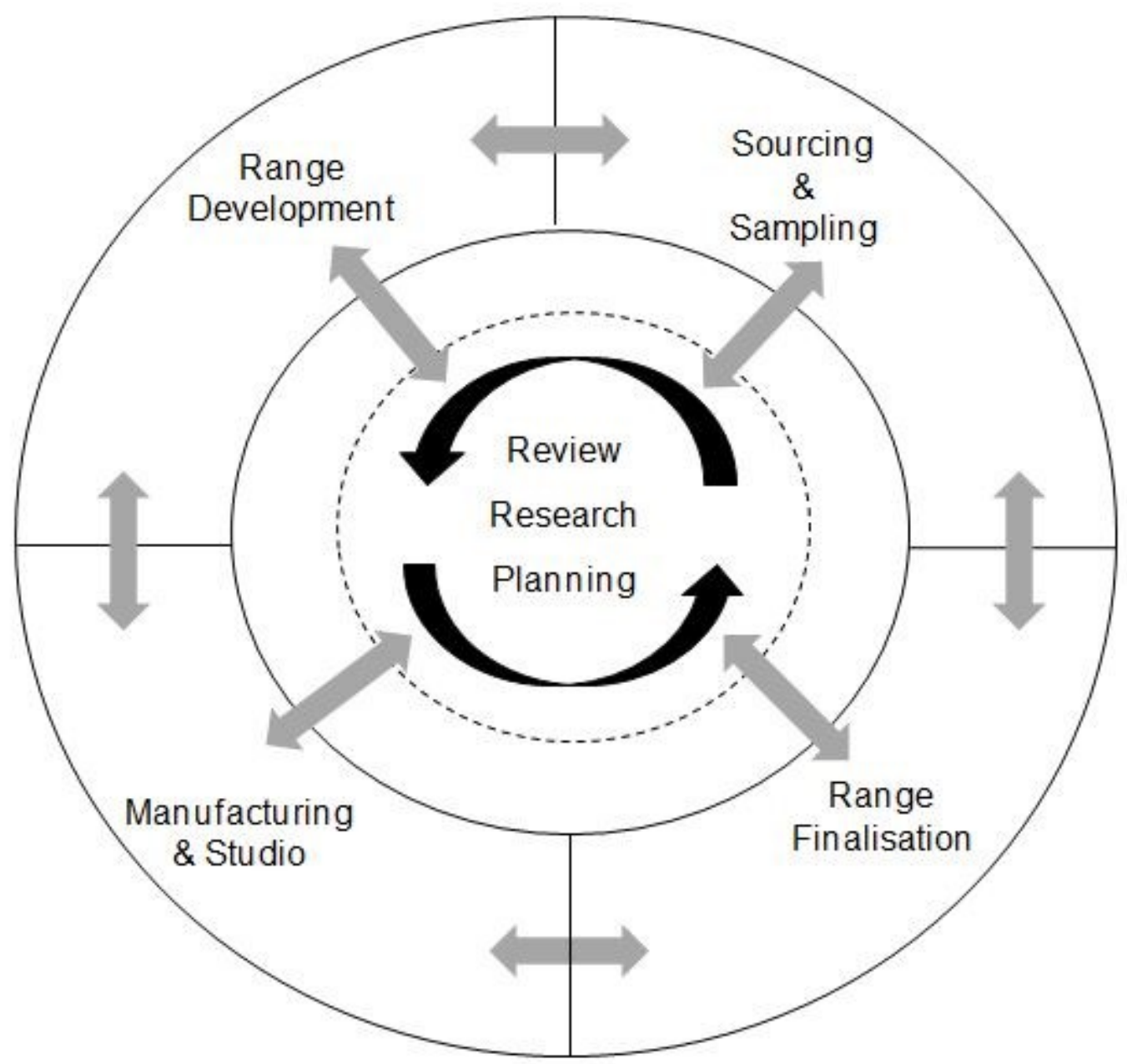

Figure 2, Theoretical Model for Fashion Product Development Process (FPDP) for On-line Fast Fashion Retailers.

This is a circular model that identifies the new stage of Studio within the process. This has not been seen previously in FPD process models (May-Plumlee and Little, 1998; Lea Wickett, Gaskill and Damhorst, 1999; May-Plumlee and Little, 2006; Goworek, 2010; Moretti and Braghini Junior, 2017) or addressed in the fashion product development literature. The model illustrates the process as circular rather 
than linear and has the central stage of Research, Review and Planning (RRP) which is a necessary activity and, in many cases, the starting point for the product development process. This central stage is continuous and flexible and will impact product development decisions influencing every stage of the process. As products move forwards and backwards throughout the process in order to keep the product development as accurate and specific as possible to the brand and consumer needs and to meet the selling and delivery schedule. Being central within the process it enables products to always be reviewed during their development, the arrows within the process model reflect the continuous lines of communications availability to flow and move between stages when needed. Therefore, the process is not a sequential or linear process as previously documented but likely to be iterative, and much more agile and flexible dependent upon product type and retail outlet. It would seem for online fast fashion retailers no product range is ever really finalized; products can enter at almost any stage of the fashion product development process regardless of where they originate from and the final sales objective. Changes are applied when necessary, authority and decision making is not delayed, and time, speed and cost are the main objectives for all within the process.

\section{Conclusion}

This research has established that there is a contribution to knowledge not previously addressed in the published Fashion Product Development literature. It appears that online fast fashion retailers have significantly amended and modified the product development process to a more streamlined and simplified version. Previously within the fashion product development literature and the process models established there was no differentiation between the different types of retailers, their market share, and type of business, volume of product, and methods of retailing when discussing the fashion product development process. It is also interesting to note that product classification in preprocess can influence the type of product development process required and which stages are required within the process. The challenging time scales, short product life cycles, unpredictability and management of the process that are continuous issues for online fast fashion retailers has been addressed in this research. This idea may be of value to product development management for all disciplines with challenging, unpredictable products. The key observation is that Fashion Product Development for online fast 
fashion retailers is not precisely sequential but a series of linked activities that overlap, requires concise planning for time, resources, and people in order to address the implications of rapidly changing consumer demand and speed of delivery to the market. These considerations need to be managed continually in order to ensure that the most effective methods and processes are used to address the unique challenges of the fashion industry. 


\section{References}

Aguinaldo, J. P. (2004) 'Rethinking Validity in Qualitative Research from a Social Constructionist Perspective: From "Is this Valid Research?" to "What is this Research Valid for?"', The Qualitative Report, 9(1), pp. 127-136. Available at: http://www.nova.edu/ssss/QR/QR9-1/aguinaldo.pdf?q=validity.

Antwi, S. K. and Kasim, H. (2015) 'Qualitative and Quantitative Research Paradigms in Business Research: A Philosophical Reflection Performance Management Practices in the Ghanaian local government system View project', European Journal of Business and Management, 7(3), pp. 217-226. Available at: https://www.researchgate.net/publication/295087782.

Barnes, L. and Lea-Greenwood, G. (2006) 'Fast fashioning the supply chain: shaping the research agenda', Journal of Fashion Marketing and Management, 11, pp. 571586.

Bazeley, P. (2013) Qualitative Data Analysis Practical Strategies. London: SAGE Pulblications.

Bhardwaj, V. and Fairhurst, A. (2010) 'Fast fashion: Response to changes in the fashion industry', International Review of Retail, Distribution and Consumer Research, 20(1), pp. 165-173. doi: 10.1080/09593960903498300.

Boddy, C. R. (2016) 'Sample size for qualitative research', Qualitative Market Research, 19(4), pp. 426-432. doi: 10.1108/QMR-06-2016-0053.

Boujut, J. F. and Laureillard, P. (2002) 'A co-operation framework for productprocess integration in engineering design', Design Studies, 23(6), pp. 497-513. doi: 10.1016/S0142-694X(01)00044-8.

Cachon, G. P. and Swinney, R. (2011) 'The Value of Fast Fashion: Quick Response, Enhanced Design, and Strategic Consumer Behavior', Management Science, 57(4), pp. 778-795. doi: 10.1287/mnsc.1100.1303.

Caro, F. and Martinez, V. (2014) Fast Fashion: Business Model Overview and Research Opportunities, Retail Supply Chain Management: Quantitative Models and Empirical Studies.

d'Avolio, E., Bandinelli, R. and Rinaldi, R. (2015) 'Improving new product 
development in the fashion industry through product lifecycle management: a descriptive analysis', International Journal of Fashion Design, Technology and Education, 8(April), pp. 108-121.

Doris, H., Kinade, C. R. and Gibson, F. Y. (2007) 'Concurrent engineering for product devlopment in mass customization for the apparel industry', International Journal of Operations \& Production Management, 27(6), pp. 627-649. doi: 10.1108/S1479-3563(2012)000012B007.

Edited (2019) 'Data Analytics'. www.Edited.com.

Gaskill, L. R. (1992) 'Toward a Model of Retail Product Development: A Case Study Analysis', Clothing and Textiles Research Journal, 10(4), pp. 17-24. doi: 10.1177/0887302X9201000403.

Goworek, H. (2010) 'An investigation into fashion product development processes for UK fashion retailers: A multiple case study', Journal of Fashion Marketing and Management: An International Article information :, 14(4), pp. 648-662.

Goworek, H. and McGoldrick, P. (2015) Retailing marketing managment: principles and practices. Harlow: Pearson Education Ltd.

Grose, V. (2012) Concept to Customer. London: AVA Publishing.

Hammersley, M. (2013) What is Qualitative Reserach. London: Bloomsbury.

Hart, S. (1996) New Product Development, New Product Development. Edited by S. Hart. London: The Dryden Press.

Hart, S. J. and Baker, M. J. (1994) 'Processing Model of New Product Development', International Marketing Review, 11(1), pp. 77-92.

Keiser, S. and Garner, M. (2012) Beyond design : the synergy of apparel product development. 3rd edn. New York: Fairchild Publications Inc.

Kincade, D., Gibson, F. and Regan, C. (2007) 'Concurrent engineering for product development in mass customization for the apparel industry', International Journal of Operations \& Production Management, 27(627-649). doi:

10.1108/17465681011017255.

Krishnan, V. and Ulrich, K. T. (2001) ‘Product Development Decisions: A Review of 
the Literature', Management Science, pp. 1-21.

Lamb, J. M. and Kallal, M. J. (1992) 'A Conceptual Framework for Apparel Design', Clothing and Textiles Research Journal, 10, pp. 42-47.

Lea Wickett, J., Gaskill, L. R. and Damhorst, M. L. (1999) 'Apparel Retail Product Development: Model Testing and Expansion', Clothing and Textiles Research Journal, 17(1), pp. 21-35. doi: 10.1177/0887302X9901700103.

Mahajan, V. and Wind, Y. (1988) 'New product forecasting models', International Journal of Forecasting, 4, pp. 341-358. doi: 10.1016/0169-2070(88)90102-1.

May-Plumlee, T. and Little, T. (2001) 'Consumer purchase data as a strategic product development tool', Journal of Textile and Apparel Technology and ..., 1(3), pp. 1-10.

May-Plumlee, T. and Little, T. J. (1998) 'No-interval coherently phased product development model for apparel', International Journal of Clothing Science and Technology, 10(5), pp. 342-364.

May-Plumlee, T. and Little, T. J. (2006) 'Proactive product development integrating consumer requirements', International Journal of Clothing Science and Technology, 18(1), pp. 53-66.

McCormick, H. et al. (2014) 'Fashion retailing - past, present and future', Textile Progress, 46(3), pp. 227-321.

McCormick, H. and Livett, C. (2012) 'Analysing the influence of the presentation of fashion garments on young consumers'online behaviour', Journal of Fashion Marketing and Management, 16(1), pp. 22-41. doi: 10.1108/03090560410539302. Mintel (2018) Clothing Retailing.

Mintel (2019) Womenswear.

Moretti, I. C. and Braghini Junior, A. (2017) 'Reference model for apparel product development', Independent Journal of Management \& Production, 8(1), pp. 232-262. doi: $10.14807 /$ ijmp.v8i1.538.

Nash, J. (2019) 'Exploring how social media platforms influence fashion consumer decisions in the UK retail sector', Journal of Fashion Marketing and Management, 
23(1), pp. 82-103. doi: 10.1108/03090560410539302.

Pitimaneeyakul, U., Labat, K. L. and Delong, M. R. (2004) 'Knitwear Product Development Process ':, Clothing and Textiles Research Journal, 22(3), pp. 113121. doi: $10.1177 / 0887302 \times 0402200302$.

Silva, R. and Rupasinghe, T. (2016) 'Characterization of new product development NPD models applicable to enhance the overall performance of the apparel industry', International Journal of Textile and Fashion Technology, 6(3), pp. 1-14.

Silvermann, D. (2014) Interpreting Qualitative Data. 5th edn. London: SAGE Pulblications.

Tran, Y., Hsuan, J. and Mahnke, V. (2011) 'How do innovation intermediaries add value? Insight from new product development in fashion markets', $R$ and $D$ Management, 41, pp. 80-91.

Trott, P. (2008) Innovation Management and new product development. 4th edn. Prentice Hall.

Tyler, D., Heeley, J. and Bhamra, T. (2006) 'Supply chain influences on new product development in fashion clothing ', Journal of Fashion Marketing and Management: An International Article information:, 10(3), pp. 316-328.

Vojak, B. A., Price, R. L. and Griffin, A. (2012) 'Serial Innovators: How Individuals Create and Deliver Breakthrough Innovations in Mature Firms', ResearchTechnology Management, 55(6), pp. 42-48. doi: 10.5437/08956308x5506899.

Vojak, R. et al. (2010) 'Corporate innovation', in Froderman, R., Thompson Klein, J., and Mitcham, C. (eds) Oxford Handbook of Interdisciplinarity. New York: Oxford University Press, p. 551. 
https://www.ft.com/content/56d880f8-dee2-11e9-9743-db5a370481bc 